\title{
Evaluating Factors Related to the Abuse of Oral Corticosteroids among Community Pharmacy Customers: Using Theory of Reasoned Action
}

Bashar G. Alfetlawi, BS Pharm, PG Diploma ${ }^{1}$; Ali Azeez Al-Jumaili, BS Pharm, MS, MPH, PhD, ${ }^{2,3}$; Munaf H Zalzala, BS Pharm, MS, PhD 3 ${ }^{1}$ University of Al-Qadisiyah College of Pharmacy, Al-Qadisiyah, Iraq; ${ }^{2}$ The University of lowa College of Pharmacy, USA; ${ }^{3}$ University of Baghdad College of Pharmacy, Baghdad, Iraq

\begin{abstract}
Introduction: Although it is discouraged, community pharmacy customers can obtain oral corticosteroids (OCSs) without prescriptions from some community pharmacies in Iraq. Medication abuse is defined as the use of medication for non-medical reasons.

Objectives: The study aimed to determine demographics, beliefs, and perceptions associated with the abuse of oral corticosteroids for non-illness reasons among community pharmacy customers.

Methods: This cross-sectional study was conducted in fall 2018 in four provinces in Iraq. Customers of 19 community pharmacies asking for OCSs for themselves without a prescription were administered a paper survey. This study used the Theory of Reasoned Action (TRA) to measure the relationship between the motivational factors and the abuse of OCSs. Logistic regression analysis was conducted to evaluate the relationships between the use of OCSs for non-illness and six TRA factors: Normative belief, behavioral belief, evaluation of the behavior, motivation to comply, subjective norms and attitude toward behavior.

Results: The study enrolled 141 participants (98 women and 43 men) taking asking for OCSs without prescription. Dexamethasone was the most commonly used OCSs (59.6\%). Friends were the primary recommenders for corticosteroids abuse (28.4\%). The main reasons for using OCSs were to increase appetite and gain weight (53.9\%). Approximately one-third (36.2 \%) of the participants gained weight after using OCSs. The regression analysis of the TRA variables showed two factors were significantly related to the abuse of OCSs. Age had a significant inverse relationship with the abuse of OCSs and the "good appearance" belief had a significant positive association with OCS abuse.

Conclusion: Some Iraqi community pharmacy customers use non-prescribed oral corticosteroids to increase appetite and gain weight. Improve body appearance represents the dominant incentive that urges people to use OCSs without prescription. Health officials and healthcare practitioners need to promote people's awareness about the risks of misusing OCSs through education programs and advertisements in public health settings, media, and social media.
\end{abstract}

Keywords: Abuse, oral corticosteroids, community pharmacy, Theory of Reasoned Action

\section{Introduction}

Corticosteroids have an essential role in treating numerous symptoms and inflammatory diseases. They can be used to treat different endocrine, rheumatologic, pulmonary, hematologic, ophthalmologic, gastrointestinal and dermatologic disorders. (1) However, these drugs cause a wide range of adverse drug reactions (ADRs) including Cushingoid appearance, weight gain, osteoporosis, fractures, psychiatric and cognitive disturbances, immunosuppression, skin atrophy, acne, hypertrichosis, and hypopigmentation. $(1,2)$ The ADRs increasingly occur when corticosteroids are used without medical supervision and primarily when they are used for nonillness related reasons. $(3,4)$

Corresponding author: Ali Azeez Al-Jumaili, MPH, PhD The University of lowa College of Pharmacy, USA University of Baghdad College of Pharmacy, Baghdad, Iraq Email: aliazeezali-aljumaili@uiowa.edu
It is essential to distinguish between misuse and abuse of medications. Medication misuse has been defined as the incorrect use of medication for a medical purpose (e.g. incorrect dose or duration of action). On the other hand, medication abuse has been defined as the use of medication for a non-medical reason. (5)

In developing countries, OCSs can be obtained without prescription (behind the counter). In African and Asian countries including Iraq, consumers can obtain prescribed only medications (POMs) from some community pharmacies without medical supervision for different reasons despite being legally unaccepted. This uncontrolled dispensing may lead to high incidence of abuse. Studies in Iraq, Egypt and China showed a wide variety of reasons come into play regarding POMs access including cultural beliefs, shortage or absence of social security service and low income, which may limit access to healthcare providers, in addition to inadequate level of regulatory enforcement. (6-10) Analgesics, cough and cold preparations, and laxatives are the most common abused medications in Middle East countries. $(11,12)$ In Iraq, lacking 
official enforcing of prescription necessity and absence of auditing on pharmacy-kept prescriptions may explain patient access to most of medication types without prescription in community pharmacies. In most circumstances (except for controlled substances), Iraqi patients can keep doctor prescriptions after receiving POMs from community pharmacies to use it for refilling with or without doctor permission. It is worth noting that almost all Iraqi healthcare settings still do not implement electronic prescription. Nevertheless, pharmacies in governmental hospitals and healthcare setting require new prescriptions for any medication (11).

In addition to absence of enforcing governmental regulations, cultural believes (e.g., linking beauty to obesity) and inadequate awareness about the side effects play a critical role in the wide spread of corticosteroids abuse in developing countries. $(3,4,13,14)$ In a pilot study in Baghdad about self-medication, Ibrahim and colleagues found that $2.8 \%$ of the participants use systemic corticosteroids without prescription. (7) Mansour and colleagues conducted a hospital-based study of prevalence and attitude toward using oral or parenteral corticosteroids without prescription in Basra, Iraq. They found that prevalence of corticosteroids use without prescription is $2.6 \%$ and most of the study subjects believed that using systemic corticosteroids without medical supervision is safe. (3) A study in Morocco assessed cultural perceptions and weight gain practices among Moroccan Saharawi women using traditional meals and oral corticosteroids (OCSs). It found OCSs were used to increase appetite and weight to help the women to be attractive (culturally). (13) A study in Congo evaluated the prevalence of OCSs abuse among Kinshasa population and found they were misusing dexamethasone and cyproheptadine combination to be beautiful. (14)

This study used Theory of Reasoned Action (TRA) to measure the relationship between the motivational factors and the abuse of oral corticosteroids. The TRA was selected because it has six domains (normative belief, behavioral belief, evaluation of the behavior, motivation to comply, subjective norms and attitude toward behavior) (15) with high potential to explain the reasons of OCS abuse in a developing country (like Iraq). In contrast, all the previous studies in the literature did not use a theoretical framework to assess the motivational factors behind the corticosteroid abuse. Unlike the abuse of anabolic steroids, which had more attention and studies, the abuse of OCSs has been understudied. Thus, there is a need for such research to enhance awareness about the adverse drug events resulted from such behavior. The study objective was to determine demographics, beliefs, and perceptions associated with the abuse of oral corticosteroids for non-illness reasons among Iraqi community pharmacy customers.

\section{Methods}

This cross-sectional study was community pharmacy-based survey. It was conducted in four Iraqi middle and southern provinces including Al-Diwaniyah, Al-Muthanna, Najaf, and Karbala (out of 19 provinces in Iraq), in fall 2018. The study was conducted in a convenience sample of 19 independent community pharmacies (ten in Al-Diwaniyah, five in Najaf and two in each of Al-Muthanna, and Karbala). The inclusion criteria included community pharmacy customers asking for oral corticosteroids without a prescription, aged fifteen years and older, purchasing the medicines for themselves, and verbally agreed to participate.

In this study, we used Theory of Reasoned Action (TRA) to develop variables (survey items) predicting the pharmacy customer behavior of using OCS without prescription (abuse of OCS). Six survey items were designed to represent the six domains of the TRA (i.e. one variable for each domain): Normative belief, behavioral belief, evaluation of the behavior, motivation to comply, subjective norms and attitude toward behavior (Figure 1). (15) An expert in Social and Administrative Pharmacy (area of the study) involved in the developing of the questions. We developed one variable per domain to shorten the survey since customers are usually in hurry and they received no incentives to spend long time. The content and face validities of the variables were evaluated by an expert in the field. The TRA was chosen because it can explain the relationship between people behavior (the use of OCSs without prescription) and their beliefs, subjective norms, attitudes, and intentions to abuse OCSs (Figure 1). (15)

The anonymous survey items included closed and partially open-ended questions and consisted of five sections. The first section included questions about sociodemographic characteristics which are gender, age, and educational level. The second section investigated the frequency and duration of oral corticosteroid use. The third section identified the source of recommendation about corticosteroids use, patient awareness about side effects and patient's chronic diseases. The fourth section searched types of corticosteroids used, indications, and most commonly possible adverse effects. In the last part, the questionnaire assessed the attitudes and beliefs of the respondents based on the TRA (15) and 5-point Likert's scale was used (strongly disagree, disagree, neutral, agree and strongly agree).

Consecutive customers that ask for oral corticosteroid without prescription were invited to participate in the study. The characteristics of non-participants were not recorded. The community pharmacists who provided the medication to patients were the same who obtained verbal consent from participants. After obtaining the verbal consent, the pharmacist administered the paper survey and reported participant answers. The pharmacists were trained by the researcher to handle the survey and answer any participant questions. The pharmacists were doing their regular duties and the research imposed no restrictions on their professional decisions regarding dispensing of OCS without prescription. Each survey took about 5-10 minutes to be completed. Arabic version of the 
survey was used to overcome participants' language barrier. The questionnaire was first developed in English and then translated into Arabic. Consequently, backward translation was conducted. The survey was pretested in a pilot study and revised according to the feedback from the pilot study.

The participation was completely voluntary, and no incentive was offered to the participants. The ethical committee at the University of Baghdad College of Pharmacy approved the study proposal.

\section{Statistical Analysis}

The Statistical Package for Social Sciences program (SPSS) version 24 (IBM SPSS Statistics, Armonk, NY, USA) was used for data analysis. The participants' age was expressed as mean, range, and standard deviation. The categorical variables were expressed as frequencies and percentages. The P-value of less than 0.05 was considered statistically significant. In this study, we defined "abuse" as using OCS without prescription for nonillness conditions. Logistic regression analysis was conducted to evaluate the relationships between the binary dependent outcome variable (use of OCSs for non-illness reasons vs illness reasons) and eight independent variables. They included gender, age, and six variables represent the TRA six domains: Normative belief, behavioral belief, evaluation of the behavior, motivation to comply, subjective norms and attitude toward behavior. The net agreement responses included "strongly agree and agree", while net disagreement responses included "strongly disagree and disagree" for each statement.

\section{Results}

The study enrolled 141 pharmacy customers (98 women and 43 men) asking for OCSs without prescription (Table 1). Their average age was $28.4( \pm 10.9)$ years old. More than half of the participants ( $\mathrm{N}=75,53.2 \%)$ had a secondary school degree or lower level of education. Dexamethasone was the most common used OCSs ( $N=84,59.6 \%)$. Weight gain ( $N=51,36.2 \%)$ and repeated infections ( $N=41,29.1 \%$ ) were the most common side effects developed among the participants. Once daily was the most common frequency of OCSs used by the participants $(\mathrm{N}=57,40.4 \%)$. Approximately half $(\mathrm{N}=68,48.2 \%)$ of the participants were taking OCS for less than three months. Participants' friends were the main recommenders ( $N=40,28.4$ $\%)$ for the use of OCSs without a prescription (Figure 2). The most common chronic disease/symptom among participants was poor vision (29.1\%) (Table 1).

More than half of the participants ( $N=76,53.9 \%)$ used OCSs for non-illness reasons to increase appetite and/or gain weight (Figure 2). About half $(\mathrm{N}=71,50.4 \%)$ of the respondents believed there is no need for a prescription to use OCSs. The unawareness about OCSs adverse effects was abundant among participants $(\mathrm{N}=93,66 \%)$ while only $48.2 \%(\mathrm{~N}=68)$ of them asked a pharmacist before using OCSs (Table 1 ).
The results of the TRA-based six items about participant's beliefs and perceptions were toward the agreement (agree and strongly agree) to abuse of OCSs (Figure 3). Most of the participants believe that OCSs improve their health and appearance. According to the results of the TRA items, $63.8 \%$ of friends believe the use of OCSs is helpful for health, and $46.1 \%$ of friends were using OCSs (Figure 3).

Binary logistic regression analysis was used to measure the influence of TRA variables on the abuse of OCSs (use for nonillness reasons) (Table 2$)$. The analysis showed significant $(P<$ 0.05 ) negative relationship between age (Odds ratio (OR): 0.93 , $95 \% \mathrm{Cl}(0.88-0.98))$ and abuse of OCSs. In contrast, there was no significant relationship between gender and abuse of OCSs. This result means older participants were less likely to abuse OCSs (use for non-illness reasons). The analysis showed the behavioral belief of improving appearance had significant positive relationship with OCSs abuse for non-illness reasons (Odds ratio (OR): $2.61,95 \% \mathrm{Cl}(1.37$ - 4.95)). This finding indicates that the participants believe that OCSs use improves their appearance which consequently will encourage them to use OCSs. The regression analysis also indicated that all other participants' beliefs, subjective norms, perceptions and intention toward abuse of OCSs had no significant association with OCSs abuse.

\section{Discussion}

Although this study was not the first study to evaluate factors related to abuse of OCSs (use for a non-illness condition without a prescription) $(13,14)$, to the best of our knowledge, this study was the first community pharmacy-based study to be conducted in more than one city. Additionally, previous studies did not adopt a theoretical framework to measure participants' beliefs and perceptions about corticosteroids abuse. In contrast, the current study implemented the TRA to develop the survey variables. (17) The TRA has been used to measure the beliefs, perceptions and attitudes of OCS abusers and to explain why they abuse OCSs.

Unlike hospital pharmacists who are restricted to dispense with the presence of new prescription only, some community pharmacists in Iraq may dispense OCSs with or without prescription. Thus, people can obtain OCSs from some community pharmacies without prescription (behind the counter) and some pharmacists dispense them even without asking about the indication. Lacking time, desire for financial profit in the absence of oversight and legal accounting may be the main reasons for dispensing OCS without asking about the indication of use. Although OCSs are not included in the list of over the counter drugs in Iraq, dispensing OCS without prescription may not lead to legal consequences on community pharmacies. In this study, we defined "abuse" as using OCS without prescription for non-illness conditions. This abuse led to serious adverse effects among the participants including repeated infections, depression and bone fractures (Table 1). 
Among the 141 participants involved in this study, there were more female participants $(69.5 \%$ ) than male (Table 1$)$, which is comparable with Mansour and his colleagues' study (69 \%). (3) That can be attributed to Iraqi culture since some women prefer moon-like face and increase their weight using OCSs to look beautiful. On the other hand, in Morocco and Congo studies, women were the only abusers. $(15,16)$ In the Moroccan study, women used traditional meals, low physical activities in addition to OCSs to increase their weight (13).

Dexamethasone was the most frequently abused OCS (59.6\%) which is in line with hospital-based study finding (64.2\%). (5) This popularity between abusers could be related to high glucocorticoid (GC) properties of dexamethasone over other OCSs in addition to its low price. As well as, half of the participants in the current study were taking OCSs for weight gain which was the same reason in other studies. $(3,13,14,16)$ Furthermore, we found that weight gain was the most commonly reported side effect, but it was wanted effect by more than half of the participants (Table 1). Similarly, studies in Morocco and Congo found that weight gain and being culturally beautiful (fatty) was the main reasons for abuse particularly among women. $(13,14)$

Approximately half (46.8\%) of the participants received a postsecondary school education most likely because college education at public universities is usually free in Iraq. Although the participants received higher education, they still abused OCSs. Most of the participants believe that OCSs improve their health and appearance (Figure 3). Additionally, $66.0 \%$ of the participants were unaware about OCS adverse effects. An Iraqi health literacy study found that level of education is not always associated with high health literacy. (17) Thus, people could have high education, but still do not know adequate information about their medications. The previous study in Congo found nearly the same percentage of participants with high education, while the study in Morocco found that most participants $(62.2 \%)$ never attended school. $(13,14)$ To promote people awareness and knowledge about the adverse effects of OCSs, community pharmacists need to counsel people about them before dispensing OCSs.

Once daily (40.4\%) of OCSs was the predominant regimen used by participants which is the same as what the Congo study indicates. (16) This may be explained by participants may believe that is the safest and still effective regimen to be used, which may explain why half of the participants did not consult pharmacist before using OCSs. Approximately half (48.2\%) of the participants used OCSs for less than three months while a previous hospital-based study found the average duration of use was $3.7( \pm 3.5)$ years. (5) This difference may be due to difference in the setting of the study. In contrast, the Congo study found the duration of use was more than six months. (16) In general, serious side effects usually occur when OCSs are used for long-term.
In this study, $66 \%$ of the participants were unaware of OCS adverse effects which may lead to believe that OCSs do not require a prescription. Similarly, a previous study found that $83.5 \%$ of OCSs abusers thought that their use was safe. (5) Those findings support the fact that half of the participants did not ask a pharmacist before using OCSs.

According to the regression analysis, the participant age was a significant indicator of OCS abuse. Older participants were unlikely to use OCSs for non-illness reasons ( $P$-value $<0.05$ ). Improving appearance was the only belief that significantly ( $P$ value $<0.05$ ) encourages participants to abuse OCSs for nonillness reasons (Table 2). The findings of the current study are in line with those of a previous study which indicated that younger participants who are seeking to align their appearance with culturally imposed standards of beauty were the main OCSs abusers. $(5,16)$ Two-third $(66.1 \%)$ of the participants agreed that OCS-induced moon face will improve their mood. However, this item had non-significant association with the outcome (abuse of OCSs).

Friends and family were the most common non-doctor people who give advice to use OCSs (49.0\%) for participants while a previous study found participants themselves were selfrecommenders (42.2\%) of OCSs. (5) According to the results of the TRA items, $63.8 \%$ of friends believe the use of OCSs is helpful for health, and $46.1 \%$ of friends were using OCSs (Figure 3). Self-behavior of participants to use OCSs may be influenced by friends' beliefs and actions (Figure 1). However, according to the regression analysis, the two subjective norm items were not significantly associated with the abuse of OCSs (Table 2).

The results of the TRA-based six items about participant's beliefs and perceptions were toward the agreement (agree and strongly agree) to abuse of OCSs (Figure 3). That means there is generally accepted belief and attitude towards abuse of OCSs among the participants and their family and friends. This attitude would become an intention to abuse OCSs. Subsequently, the participant intention would transform to behavior (OCSs abuse) (Figure 1).

The study had some limitations. The sampling of community pharmacies was convenience. There was one item (variable) for each of the six TRA domains. The study was conducted in four out of 19 Iraqi provinces.

\section{Conclusions}

In the studied four Iraqi provinces, OCSs are used without prescription to increase appetite and gain weight. Having culturally accepted appearance represents the dominant incentive that urges people to abuse OCSs. Younger people are more likely to abuse OCSs. Friends are the primary recommenders of OCS abuse. Dexamethasone is the predominant abused OCS. Most people who abuse OCSs are unaware of their serious adverse effects and think that OCSs can be used without a prescription. The TRA can be used to 
investigate the impact of people's beliefs and perceptions on their OCS abuse behavior.

Community pharmacists can enhance people knowledge about the adverse effects of OCS through counseling before dispensing. Finally, Iraqi health officials need to promote people awareness about the risks of misusing OCSs without medical supervision through education programs and advertisements in public health settings, media, and social networks.

\section{Conflict of Interest: None}

\section{References}

1. Liu D, Ahmet A, Ward L, Krishnamoorthy $P$, Mandelcorn ED, Leigh $\mathrm{R}$, et al. A practical guide to the monitoring and management of the complications of systemic corticosteroid therapy. Allergy, Asthma Clin Immunol [Internet]. 2013 Aug;9(1):30. Available from: https://doi.org/10.1186/1710-1492-9-30

2. Hengge UR, Ruzicka T, Schwartz RA, Cork MJ. Adverse effects of topical glucocorticosteroids. J Am Acad Dermatol [Internet]. 2006 Jan;54(1):1-15. Available from:

http://linkinghub.elsevier.com/retrieve/pii/S0190962 205002550

3. Mansour AA, Odaa AH, Wanoose HL. Corticosteroid nonprescription use: A cross-sectional hospital-based study in basrah. Med Princ Pract. 2010;19(3):182-7.

4. Saraswat A, Lahiri K, Chatterjee M, Barua S, Coondoo A, Mittal A, et al. Topical corticosteroid abuse on the face: A prospective, multicenter study of dermatology outpatients. Indian J Dermatology, Venereol Leprol [Internet]. 2011 Mar 1;77(2):160. Available from: http://www.ijdvl.com/article.asp?issn=0378-6323

5. Wazaify M, Hughes CM, McElnay JC. The implementation of a harm minimisation model for the identification and treatment of over-the-counter drug misuse and abuse in community pharmacies in Northern Ireland. Patient Educ Couns. 2006 Dec;64(1-3):136-41.

6. Yousef AMM, Al-Bakri AG, Bustanji Y, Wazaify M. Selfmedication patterns in Amman, Jordan. Pharm World Sci [Internet]. 2008 Jan 21 [cited 2018 Apr 12];30(1):24-30. Available from: http://link.springer.com/10.1007/s11096-007-9135-x

7. R.Ibrahim I, K.Al---Jawadi H, M.Younus M. Self medication practice in Baghdad, Iraq. Australas Med J [Internet]. 2012 [cited 2018 Apr 12];5(11):601-2. Available from: http://www.ingentaconnect.com/content/doaj/1836 1935/2012/00000005/00000011/art00008
8. L. Jasim A, A. Fadhil T, S. Taher S. Self Medication Practice among Iraqi Patients in Baghdad City. Am J Pharmacol Sci [Internet]. 2014;2(1):18-23. Available from:

http://pubs.sciepub.com/ajps/2/1/4/index.html

9. El-Nimr NA, Wahdan IMH, Wahdan AMH, Kotb RE. Self-medication with drugs and complementary and alternative medicines in Alexandria, Egypt: prevalence, patterns and determinants. East Mediterr Heal J. 2015;21(4):256-65.

10. Chang J, Wang Q, Fang Y. Socioeconomic differences in self-medication among middle-aged and older people: data from the China health and retirement longitudinal study. BMJ Open [Internet]. 2017 Dec 1;7(12). Available from:

http://bmjopen.bmj.com/content/7/12/e017306.abs tract

11. Al-Jumaili AA, Hussein AH, Al-Rekabi MD, Raheem SA, Ernst EJ. Antimicrobial utilization in an Iraqi province: a comprehensive evaluation of antibiotic source and cost. Int J Pharm Pract. 2017;25(1):81-8.

12. Khalifeh MM, Moore ND, Salameh PR. Selfmedication misuse in the Middle East: a systematic literature review. Pharmacol Res Perspect. 2017;5(4):1-13.

13. Rguibi M, Belahsen R. Fattening practices among Moroccan Saharawi women. East Mediterr Heal J. 2006;12(5):619-24.

14. Mputu Malolo LC, P NM, Y NB, JA MN, D PB. Sociocultural behavior comparative study of the misuse of Cyproheptadine combined with Dexamethasone in Kinshasa population, Democratic Republic of Congo. Int J Med Res. 2017;2(4):17-22.

15. Ajzen I, Fishbein M. Understanding Attitudes and Predicting Social Behavior. Englewood Cliffs, NJ: Prentice-Hall, 1980.

16. Siddig AS, Ismail AA, Mohammed BA. Effect of medications misused for body weight gain on sodium and potassium concentration of female rabbits. GSC Biol Pharm Sci. 2018;02(01):32-7.

17. Al-Jumaili AA, Al-Rekabi MD, Sorofman B. Evaluation of instruments to assess health literacy in Arabic language among Iraqis. Res Soc Adm Pharm [Internet]. 2015;11(6):803-13. 


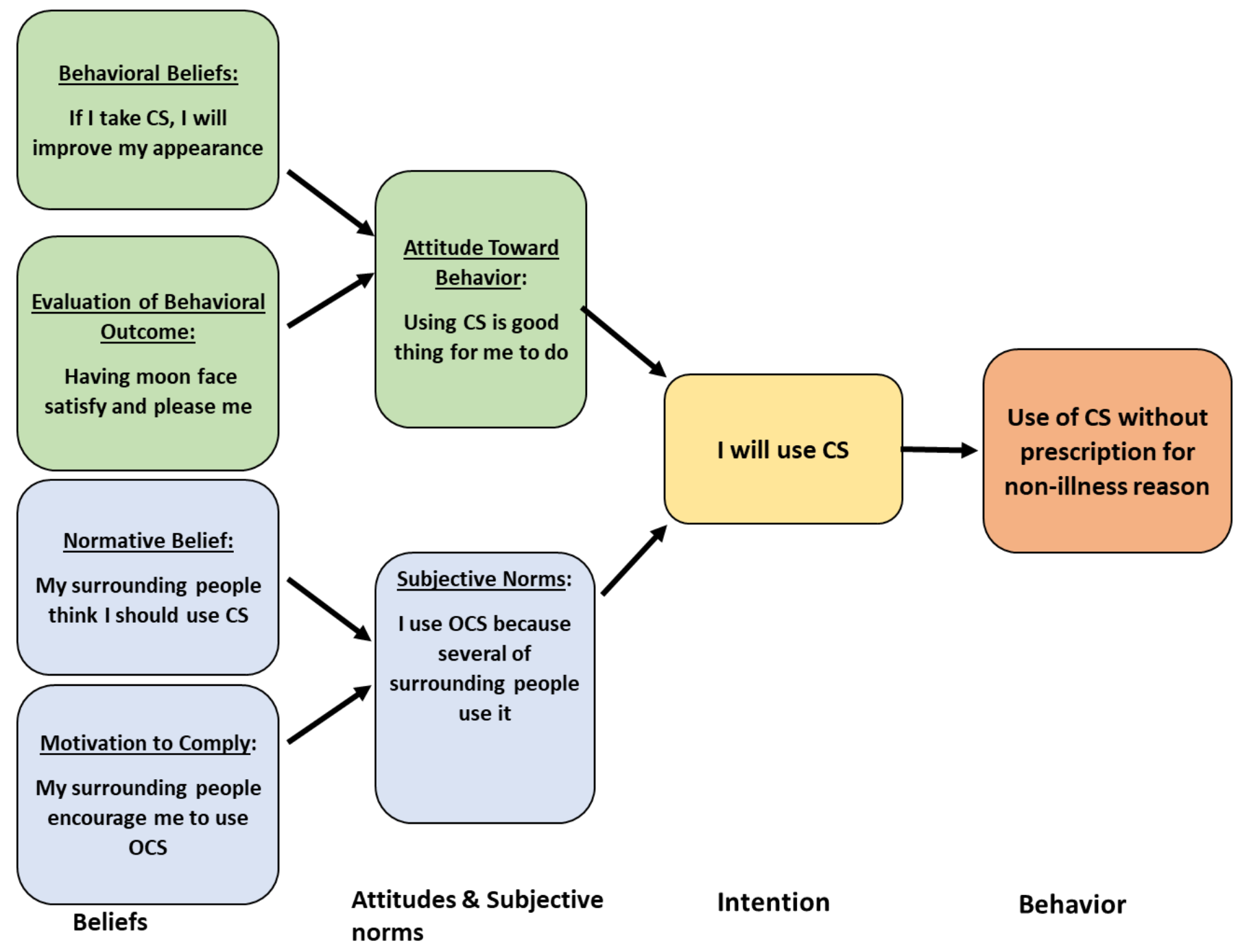

Figure 1: Beliefs, perceptions and attitudes behind the abuse of oral corticosteroids according to the Theory of Reasoned Action 
A

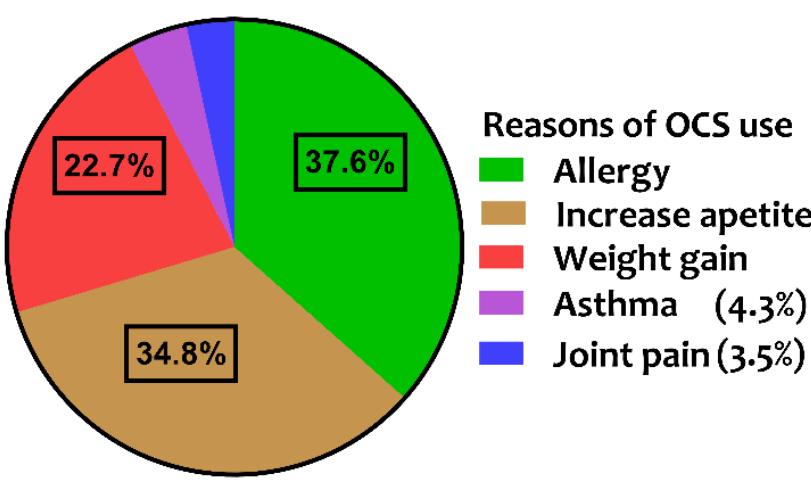

B

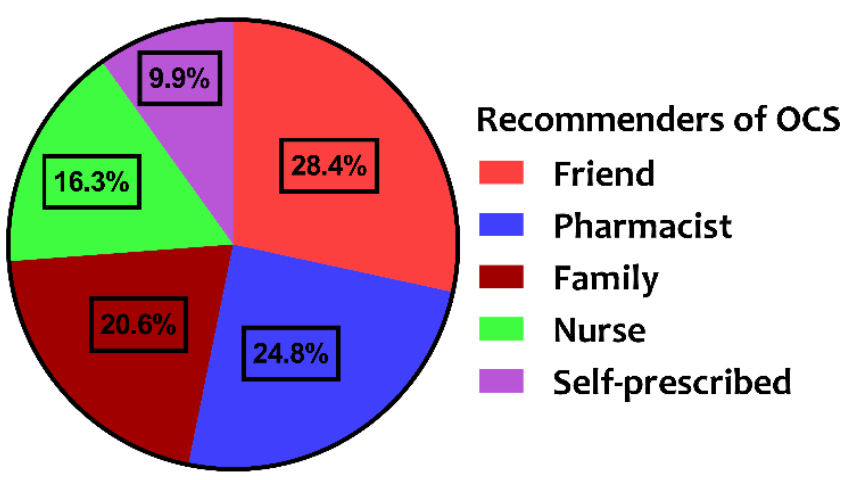

Figure 2: A- The reasons of Oral Corticosteroids Use

$53.9 \%$ of the customers used OCSs to increase appetite and/or gain weight (non-illness reasons). The total percentages are out of $102.9 \%$ because this question has option of choosing all that apply (more than one reason to use OCS).

B-The most common recommenders of OCS use without a prescription 


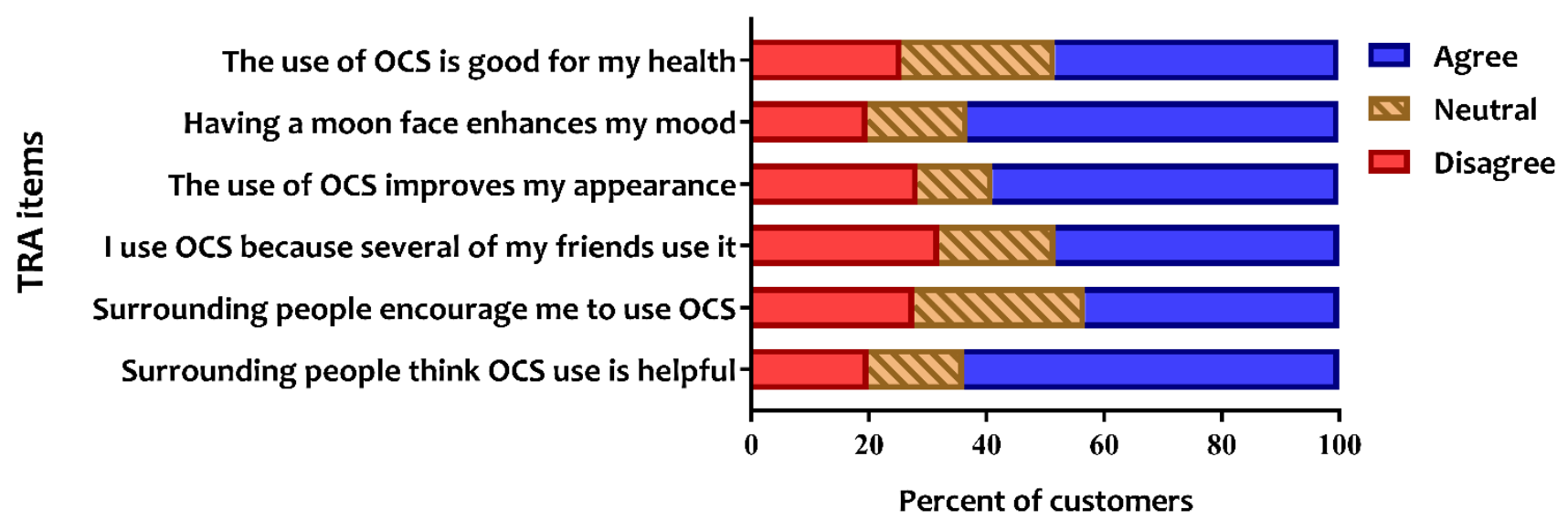

Figure 3: The percentages of participant answers to TRA perception statements about oral corticosteroid misuse (Agree $=$ agree + strongly agree; Disagree $=$ disagree + strongly disagree) An average of $54.2 \%$ of participants agreed and $25.6 \%$ disagreed to the TRA items 
Table 1: Characteristics of users and how they use oral corticosteroids

\begin{tabular}{|c|c|c|}
\hline Characteristic & Subgroups/categories & $\mathbf{N}(\%)$ \\
\hline \multirow[t]{2}{*}{ Age } & Mean \pm SD (years) & $28.4 \pm 10.9$ \\
\hline & Range (Min.-Max.) (years) & $50(15-65)$ \\
\hline \multirow[t]{2}{*}{ Gender } & Male & $43(30.5)$ \\
\hline & Female & $98(69.5)$ \\
\hline \multirow[t]{2}{*}{ Education } & Secondary school and lower & $75(53.2)$ \\
\hline & College or graduate degrees & $66(46.8)$ \\
\hline \multirow[t]{4}{*}{ Governorate } & Al Diwaniyah & $73(51.8)$ \\
\hline & Najaf & $30(21.3)$ \\
\hline & Al Muthanna & $17(12.1)$ \\
\hline & Karbala & $21(14.9)$ \\
\hline \multirow[t]{5}{*}{ Dosage Frequency } & Three times a day & $13(9.2)$ \\
\hline & Twice daily & $37(26.2)$ \\
\hline & Once daily & $57(40.4)$ \\
\hline & Every other day & $16(11.3)$ \\
\hline & Unregulated & $18(12.8)$ \\
\hline \multirow[t]{6}{*}{ OCS Usage Period } & $<1$ month & $34(24.1)$ \\
\hline & $1-3$ months & $34(24.1)$ \\
\hline & $>3-6$ months & $22(15.6)$ \\
\hline & $>6$ months -1 year & $20(14.2)$ \\
\hline & $>1-3$ years & $13(9.2)$ \\
\hline & $>3$ years & $18(12.8)$ \\
\hline \multicolumn{2}{|l|}{ Consulted a pharmacist before using } & $68(48.2)$ \\
\hline \multirow[t]{4}{*}{ Types of OCS used } & Dexamethasone & $84(59.6)$ \\
\hline & Betamethasone & $14(9.9)$ \\
\hline & Prednisolone & $41(29.1)$ \\
\hline & Others (Hydrocortisone.) & $2(1.4)$ \\
\hline \multicolumn{2}{|l|}{ Unaware about OCS adverse effects } & $93(66.0)$ \\
\hline \multirow{7}{*}{$\begin{array}{l}\text { Side effects of OCS } \\
\text { (choose more than one answer) }\end{array}$} & Weight gain & $51(36.2)$ \\
\hline & Repeated infections & $41(29.1)$ \\
\hline & Feeling depressed & $21(14.9)$ \\
\hline & Oral fungal infection & $19(13.5)$ \\
\hline & Excessive body hair (hirsutism) & $14(9.9)$ \\
\hline & Bone fracture & $2(1.4)$ \\
\hline & Others & $2(1.4)$ \\
\hline
\end{tabular}

\footnotetext{
Total number of participants is 141 .
} 
Table 2: Logistic regression table of factors influencing the abuse of oral corticosteroids

\begin{tabular}{|c|c|c|c|c|}
\hline Parameter & $\begin{array}{l}\text { Point estimate } \\
\text { (odds ratio) }\end{array}$ & \multicolumn{2}{|c|}{ 95\% Confidence limits } & P-value \\
\hline Gender (Male vs Female) & 0.99 & 0.33 & 3.04 & 0.991 \\
\hline Age & 0.93 & 0.88 & 0.98 & $0.004 *$ \\
\hline $\begin{array}{l}\text { My surrounding people } \\
\text { (family/friends) think that use of OCS is } \\
\text { helpful (normative belief) }\end{array}$ & 1.28 & 0.66 & 2.48 & 0.470 \\
\hline $\begin{array}{l}\text { My surrounding people } \\
\text { (family/friends) encourage me to use } \\
\text { OCS (motivation to comply) }\end{array}$ & 0.63 & 0.36 & 1.11 & 0.108 \\
\hline $\begin{array}{l}\text { I use OCS because several of my } \\
\text { friends use it (subjective norms) }\end{array}$ & 1.69 & 0.95 & 2.99 & 0.073 \\
\hline $\begin{array}{l}\text { I believe that the use of OCS improves } \\
\text { my appearance (behavioral belief) }\end{array}$ & 2.61 & 1.37 & 4.95 & $0.003^{*}$ \\
\hline $\begin{array}{l}\text { Having a moon face enhances my } \\
\text { mood (evaluation of the behavior) }\end{array}$ & 1.27 & 0.67 & 2.41 & 0.468 \\
\hline $\begin{array}{l}\text { The use of OCS is good for my health } \\
\text { (attitude toward behavior) }\end{array}$ & 1.14 & 0.63 & 2.07 & 0.676 \\
\hline
\end{tabular}

Total $\mathrm{N}=141$. Outcome variable = use of oral corticosteroids for non-illness reasons vs illness reasons. ( $n=76$ : to gain weight and/or increase appetite)

*Statistically significant result $(\mathrm{P}$-value $<0.05)$ 